The final publication is available at:

http://www.tandfonline.com/doi/abs/10.1080/14680629.2012.735794

Taylor \& Francis

\title{
In-place evaluation of a limestone base course modulus, using a van-integrated falling weight deflectometer (FWD) and the GeoGauge (SSG)
}

Mário Quinta-Ferreira ${ }^{\text {* }}$, Eduardo Fung ${ }^{\mathrm{b}}$, Pedro Santarém Andrade and Fernando Castelo Branco ${ }^{\mathrm{a}}$

${ }^{a}$ University of Coimbra, Ciências da Terra, Geosciences Center, Largo Marquês de Pombal, 3000-272, Coimbra, Portugal; ${ }^{b}$ Consulstrada, Rua 35 - Parque Empresarial Barreiro 13, Barreiro 2830-000 Setúbal, Portugal

A comparative evaluation of the in-place stiffness modulus using a van-integrated falling weight deflectometer (FWD) and the GeoGauge (soil stiffness gauge - SSG) was done on a limestone all-in-aggregate (AIA), used in the base course of a highway pavement. The tests were done in two campaigns, one for each unbound granular layer of $0.15 \mathrm{~m}$ thickness, along $510 \mathrm{~m}$, using five alignments. Considering the whole granular materials used, the dry unit weight $(\gamma \mathrm{d})$ is related with the stiffness modulus obtained with the SSG. The stiffness moduli obtained for the SSG and for the FWD in the same test point are not correlated. Considering as reference the equivalent modulus obtained with the FWD, the moduli computed for the 85th percentile with both the FWD and the SSG show a difference lower than 20\%. These results emphasise the possible use of the SSG as a reliable procedure for stiffness modulus evaluation of unbound limestone bases.

Keywords: base course; pavement; all-in-aggregate; stiffness modulus; FWD; GeoGauge

\section{Introduction}

The assessment of the stiffness modulus of subgrades and compacted unbound layers of road pavement foundations can be quite useful to evaluate the efficiency of the construction techniques and the suitability of the materials used, seeking to anticipate the behaviour of the road structure under traffic loads.

The current construction procedures require compacting at the optimum moisture content $\pm 2 \%$, as obtained from the laboratory standard modified effort test, to obtain the maximum dry density.

However, the variation of stiffness within this range of moisture content can be greater than the variation in the dry density, and the use of stiffness as acceptance criterion in the current construction procedures continues to require implementation (Abu-Farsakh, Alshibli, Nazzal, \& Seyman, 2004). 
The evaluation of the stiffness modulus is currently established by field test. The falling weight deflectometer (FWD) is a device that performs non-destructive in situ testing, and is widely used as a reference test to assess the quality construction of roadways, airport pavements, railway tracks and embankments.

For subgrades, the surface modulus is often estimated based on subgrade California bearing ratio (CBR). The subbase foundation surface modulus is usually obtained using the FWD or the light weight deflectometers (LWDs), which must comply with accepted testing requirements of design standards, such as the UK IAN73/06 revision 1 (2009). The LWDs are widely used for quality control and determination of the stiffness modulus due to low operating cost, to a minor potential health hazard compared with the nuclear moisture/density gauges. The LWD permits the direct determination of the stiffness modulus for pavement design.

The TRL Foundation Tester (TFT) was created in 1992 at the Loughborough University, in England, showing great similarity with the modern LWD devices. The TFT has a $10 \mathrm{~kg}$ falling mass that impacts through a rubber damper seated on a $300 \mathrm{~mm}$ plate (Fleming, Rogers, \& Frost, 1998), having a stress range up to $20 \mathrm{kPa}$. The TFT directly measures the force applied and the ground deflection.

The most common LWD was developed in Germany in 1991, and it known as the German dynamic plate (GDP) bearing tester (Nazzal, Abu-Farsakh, Alshibli, \& Mohammad, 2007). For this device, the tests are performed in accordance with the German standard TP BF-StB Part B8.3 (2003). The GDP is an alternative method to the static plate-bearing test. This tester comprises a total mass of $25 \mathrm{~kg}$ and a falling mass of $10 \mathrm{~kg}$, which drops $1 \mathrm{~m}$. The bearing plate has $300 \mathrm{~mm}$ diameter and includes a velocity transducer located at the centre of the plate to obtain the impact signal (Garcia \& Thompson, 2003).

In France, the LCPC-deflectometer and LPC-dynaplaque devices are commonly used. The Dynaplaque- 1 and Dynaplaque-2 equipment follows the French standard NF P 94-117-2 (2004), allowing to evaluate the dynamic modulus of the subgrade and selected fill of the subbase or the pavement (LCPC, 2004). The Dynaplaque- 1 can deal with modulus between 20 and $100 \mathrm{MPa}$, while the Dynaplaque-2 works in the range of 20-250 MPa. Similar to other devices, the deflection is caused by a falling weight. For the Dynaplaque-2, the falling weight has $120 \mathrm{~kg}$, falling from $0.5 \mathrm{~m}$ height onto a rigid plate, and the applied maximum force is $100 \mathrm{kN}$. The soil deflection and the impact force are measured by transducers located on the plate.

To evaluate and compare the results of both equipment used in the present study (FWD and SSG), two test campaigns were done in the left side of a two lane highway, between 10.450 and $10.610 \mathrm{~km}$ of the project, one in the lower all-in-aggregate (AIA) layer and the other in the upper AIA layer. The work was done during the construction of the A17 highway - Marinha Grande/Mira, between Tocha and Mira, in Portugal. 


\section{Equipment used}

The van-integrated FWD is a relatively heavy equipment that, according to George (2006), has been a favoured pavement evaluation method for more than two decades. In Portugal, it is the reference procedure to evaluate the stiffness modulus of road pavement foundations.

The GeoGauge (soil stiffness gauge-SSG) was selected for comparison with the van-integrated FWD due to the fact that it is a fast, easy to use and not expensive method. The selection of the SSG was based on previous works (Abu-Farsakh et al., 2004; Alshibli, Abu-Farsakh, \& Seyman, 2005; Batista, 2007; Mohammad, Nazzal, Abu-Farsakh, \& Alshibli, 2009; Nazzal, 2003; QuintaFerreira, Andrade, Branco, \& Fung, 2008b; Quinta-Ferreira, Andrade, \& Oliveira, 2008a; Sawangsuriya, 2006; Seyman, 2003).

Both the FWD and the SSG apply a dynamic force to an elastic material to estimate the elastic Modulus (Alshibli et al., 2005). Assuming that the tests are executed on an elastic half-space, when applying a superficial load, the resulting deflections are measured and used to calculate the stiffness of the layer. Considering a value for Poisson's ratio, the stiffness modulus can be computed. A Poisson ratio of 0.35 was used in the present work. The solicitations induced by the FWD (Table 1) are far greater than the ones applied by the SSG (Table 2). The intensity of the stresses and deformations produced by the SSG are common in pavements, embankment layers and foundations.

Table 1. Summary of the conditions for the tests done with the FWD.

\begin{tabular}{|c|c|c|c|c|c|c|c|c|c|c|c|c|}
\hline \multirow{2}{*}{$\begin{array}{l}\text { Peak force } \\
(\mathrm{kN})\end{array}$} & \multirow{2}{*}{$\begin{array}{l}\text { No. of } \\
\text { impacts }\end{array}$} & \multirow{2}{*}{$\begin{array}{l}\text { Radius of the } \\
\text { plate }(\mathrm{cm})\end{array}$} & \multicolumn{9}{|c|}{ Distance to geophones (cm) } & \multirow[b]{2}{*}{ Weathe } \\
\hline & & & D1 & D2 & D3 & D4 & D5 & D6 & D7 & D8 & D9 & \\
\hline 20 & 3 & 22.5 & 0 & 30 & 45 & 60 & 90 & 120 & 150 & 180 & 210 & Dry \\
\hline \multicolumn{2}{|c|}{$\overline{\text { Load Level }(\mathrm{kPa})}$} & \multicolumn{3}{|c|}{ Loaded area $\left(\mathrm{cm}^{2}\right)$} & \multicolumn{6}{|c|}{ Loading time (s) } & \multicolumn{2}{|c|}{ Poisson ratic } \\
\hline \multicolumn{2}{|l|}{62.90} & \multicolumn{3}{|c|}{1590} & \multicolumn{6}{|c|}{ Instantaneous } & \multicolumn{2}{|r|}{0.35} \\
\hline
\end{tabular}

Table 2. Summary of the conditions for the tests done with the SSG.

\begin{tabular}{llccc}
\hline $\begin{array}{l}\text { Measurement depth } \\
(\mathrm{cm})\end{array}$ & $\begin{array}{c}\text { Vibration at } 125 \mathrm{~Hz} \\
(\mathrm{~cm})\end{array}$ & No. of readings & $\begin{array}{c}\text { Radius of the ring } \\
(\mathrm{cm})\end{array}$ & Weather \\
\hline $22-31$ & $<1.27 \times 10^{-4}$ & 3 & 5.715 & Dry \\
\hline Load level $(\mathrm{kPa})$ & ${\text { Loaded } \mathrm{area}^{\mathrm{a}}\left(\mathrm{cm}^{2}\right)}^{20.6-27.6}$ & Loading time (s) & Poisson ratio & \\
\hline
\end{tabular}

${ }^{\mathrm{a} C o n s i d e r i n g}$ the outside radius of the ring.

\subsection{Van-integrated FWD}

The FWD applies an impact load to the surface of the pavement, due to the fall of a mass, inducing deflection of the foundation $(D)$ at several radial positions up to $2.5 \mathrm{~m}$ from the loading plate, which are measured by several geophones 
located on the surface of the ground. Interpretation is generally in terms of the stiffness modulus of each foundation layer. If only the central deflection is used to determine a stiffness modulus for the foundation, then an interpretation can be carried out as for other dynamic plate tests (IAN73/06 revision 1, 2009).

The apparatus used is a Carlbro model 'PRI 2100 van-integrated' (Figure 1). It measures the values of the peak force, the ground displacements and the duration of the applied load. It also allows measuring the travel distance and the temperatures of the air and on the ground. The distance of the nine geophones to the centre of the load plate can be adjusted. The impact forces can be encompassed between 10 and $250 \mathrm{kN}$, using different fall heights and masses, according to the structure of the pavement (Consulstrada, 2007a, 2007b). The main features of the van-integrated FWD used in the tests are given in Table 1.

The stiffness modulus $\left(E_{\mathrm{FWD}}\right)$, using the central deflection (D1), was computed using the Boussinesq solution:

$$
E_{\mathrm{FWD}}=\frac{\left(k\left(1-\mathrm{v}^{2}\right) \sigma R\right)}{D 1},
$$

(a)

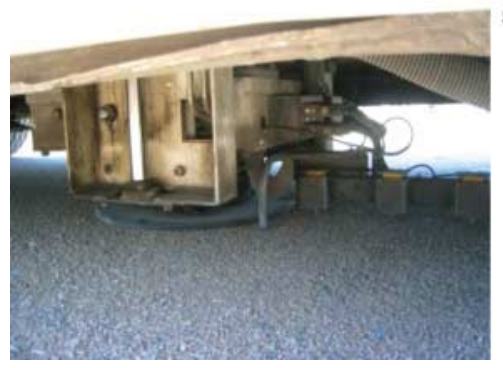

(b)

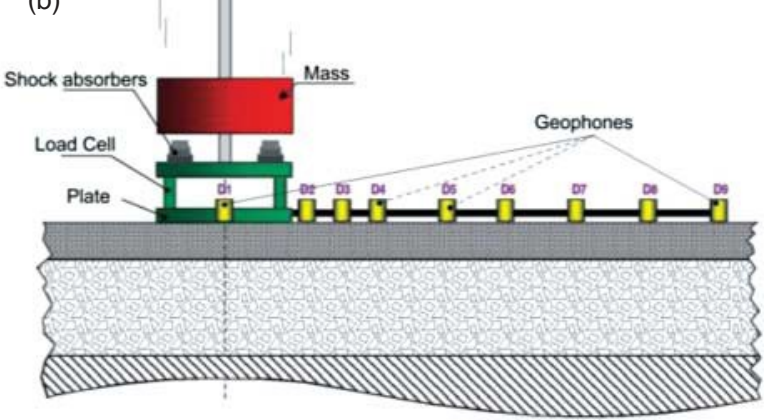

Figure 1. Van-integrated FWD: (a) van lower view and (b) schematic (Consulstrada, 2007b).

\subsection{The soil stiffness gauge (SSG)}

The GeoGauge does not measure the deflection resulting from the GeoGauge weight, rather it vibrates, producing small changes in force that produce small deflections, lower than $1.27 \times 10^{-3} \mathrm{~mm}$ at $125 \mathrm{~Hz}$. It uses 25 frequencies between 100 and $196 \mathrm{~Hz}$ and measures the resultant deflections of the ground. The material deflects an amount $\delta$, which is proportional to the outside radius of the ring foot $(R)$, Young's modulus $(E)$, the shear modulus $(G)$ and Poisson's ratio $(v)$ of the soil (Humboldt, 2007). The GeoGauge produces soil stress and strain levels common for pavement, bedding and foundation applications $(27.58 \mathrm{kPa})$. The forces applied $(P)$ and the deflections $(\delta)$ suffered by the ground are recorded. Dividing $P$ by $\delta$, the equipment determines the average stiffness $(K=P / \delta)$. Assuming a Poisson ratio for the material, previously introduced by the user, the surface stiffness module $\left(E_{\mathrm{g}}\right)$ is computed. A more detailed description of how the SSG operates, as well as some of it's more current utilizations, are explained in more detail elsewhere (Abu-Farsakh et al., 2004; Alshibli et al., 2005; ASTM D6758, 2002, 2008; Batista, 2007; Humboldt, 2007; Nazzal, 2003; Quinta-Ferreira et al., 2008a; Seyman, 2003). 
(a)

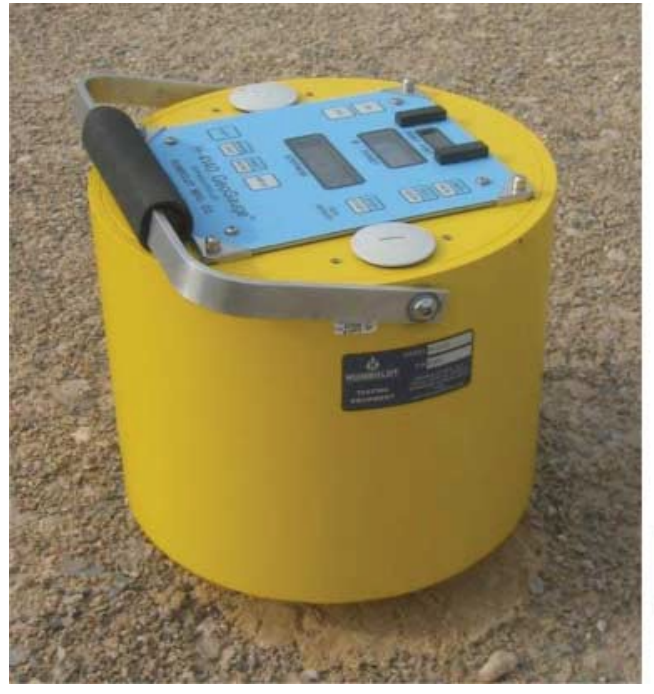

(b)

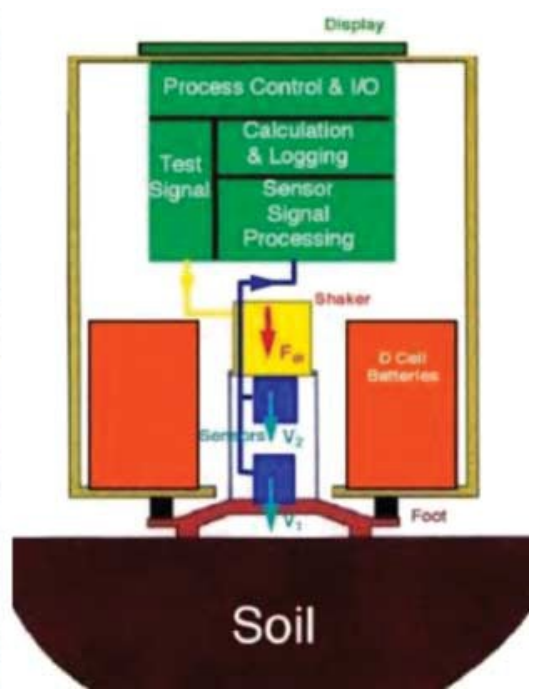

Figure 2. GeoGauge: (a) lateral view and (b) schematic (Humboldt, 2007).

The SSG used was the GeoGauge, model H-4140 (Figure 2), weighs $10 \mathrm{~kg}$, is 28 $\mathrm{cm}$ in diameter, $25.4 \mathrm{~cm}$ tall and is easy to operate by a single user. The contact between the SSG and the ground is done through the ring shape base, and a very simple preparation of the ground surface can be used to improve the quality of the measurements. A summary of the test conditions for the SSG is presented in Table 2.

\section{Materials tested}

The geology of the area where the tests were executed is constituted by sedimentary formations, outcropping Holocene aeolian sands, alluvium along the main water lines, as well as Pleistocene sandy river terraces and deposits of ancient shores. The pavement subbase are landfills constructed with the local sandy materials, mainly silty sand, but also poorly graded sand (Table 3 and Figure 3).

The aeolian sand is poorly graded (SP-SM), has $90 \%$ of sand and is non-plastic. The CBR value is $21 \%$, and according to the AASHTO soil classification system it belongs to group A-1-b(0), anticipating an excellent to good behaviour under the pavement layer. The silty sand (SM) is non-plastic and belongs to group A-1-b(0) presenting a CBR value of 39\%. 
Table 3. Summary of the properties of the materials used in the construction.

\begin{tabular}{llccc}
\hline Material & & $\begin{array}{c}\text { Poorly } \\
\text { graded sand }\end{array}$ & $\begin{array}{c}\text { Silty } \\
\text { sand }\end{array}$ & AIA \\
\hline Grain size & Gravel (\%) & 1 & 13 & 79 \\
& Sand (\%) & 90 & 81 & 16 \\
Plasticity & Clay and silt (\%) & 9 & 6 & 5 \\
Methylene blue value & $(\%)$ & $\mathrm{NP}$ & $\mathrm{NP}$ & $\mathrm{NP}$ \\
$\quad(0 / 0.075$ mm fraction) & $(\mathrm{g} / \mathrm{kg})$ & - & 3 & 4 \\
Proctor (modified effort test) & $\gamma_{\mathrm{d}}\left(\mathrm{kN} / \mathrm{m}^{3}\right)$ & 19.23 & $\mathbb{1}$ & \\
& $W_{\text {opt }}(\%)$ & 8.2 & 7.4 & 5.2 \\
CBR & $(\%)$ & 21 & 39 & - \\
Classification & USC & SP-SM & SM & - \\
Los Angeles & AASHTO & A-1-b(0) & A-1-b(0) & - \\
\hline & (\%) & - & - & 27 \\
\hline
\end{tabular}

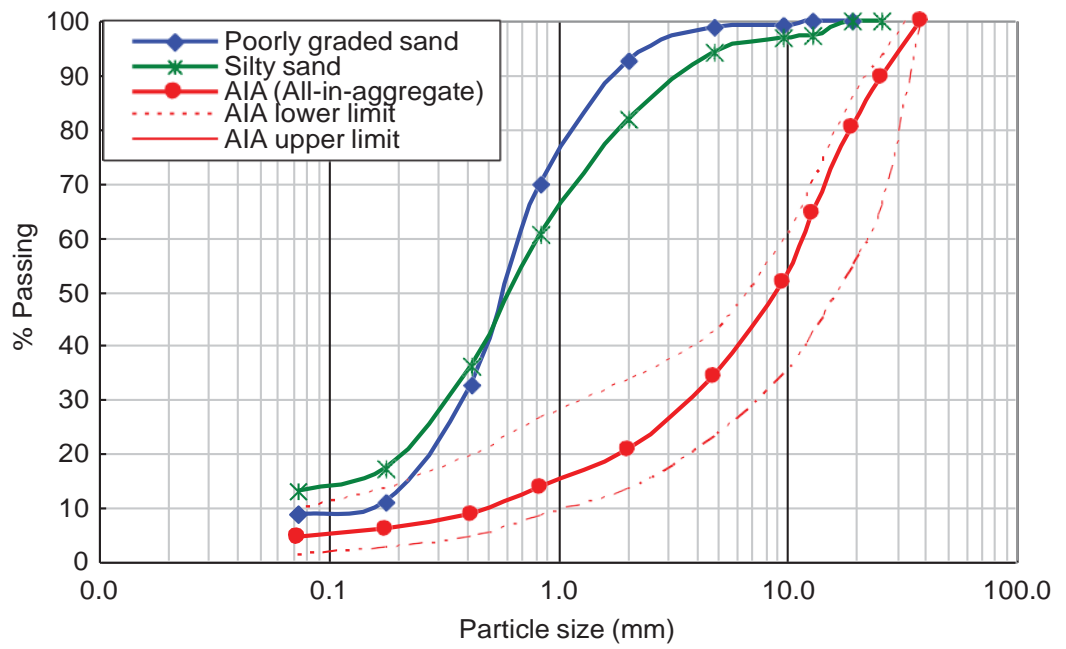

Figure 3. Grain size distributions of the AIA used in the base course and of the soils used in the construction of the subbase fill.

The granular materials used in the lower and upper layers of the base course are limestone AIA of Jurassic age, from the area of Pombal, at a distance of around $60 \mathrm{~km}$ from the construction site. The grain size distribution is shown in Figure 3, and is enclosed within the upper and lower limits required in the project. The unit weight of the limestone particles is $26.4 \mathrm{kN} / \mathrm{m}^{3}$. The Los Angeles loss of the AIA limestone is $27 \%$, while the maximum allowed in the project is $30 \%$.

The two base layers where the AIA was used were constructed with a thickness of $0.15 \mathrm{~m}$ and were compacted with six passages of a 12 ton vibrating roller, till at least $95 \%$ of the maximum unit weight of the modified effort of the Proctor test was obtained. The compaction control was currently done using a nuclear moisture/density gauge, and less frequently using the sand bottle test, mainly for verification purposes. 


\section{Work methodology}

The main scope of the work was to compare the stiffness modulus computed with the FWD methodology using back analysis, with the stiffness modulus obtained in situ with the SSG, for the AIA base course. Additionally, a summary characterisation of the natural materials used in the fill construction was also done.

To achieve the first objective, two onsite test campaigns were executed on the base course, at the left traffic way of a two lane roadway, between 10.450 and $10.610 \mathrm{~km}$ of the project. The first campaign was done after the construction of the lower AIA layer, and the second campaign, around one month later, following the construction of the upper AIA layer. Five parallel lines, away $1.7 \mathrm{~m}$, with 7-9 test locations in each line (Figure 4).

The pattern of the test locations for all apparatus (FWD; SSG and the nuclear moisture/ density gauge) in the upper layer, and for the FWD in the lower layer is shown in Figure 4(a). The spacing between test locations along each line was $20 \mathrm{~m}$ and the test locations in adjacent lines had a longitudinal offset of $10 \mathrm{~m}$.

In the lower layer for the SSG and the moisture/ density gauge, the spacing of the test locations on each line was $25 \mathrm{~m}$ and there was no longitudinal offset between adjacent lines (Figure 4(b)). Thus, in the lower layer it was not possible to establish a coincidence between most of the test locations with the two devices (Figure 4). The 35 tests done with the SSG and the nuclear moisture/density gauge in the lower layer were accomplished one day after the tests with the FWD. For the FWD 37 test locations were used.

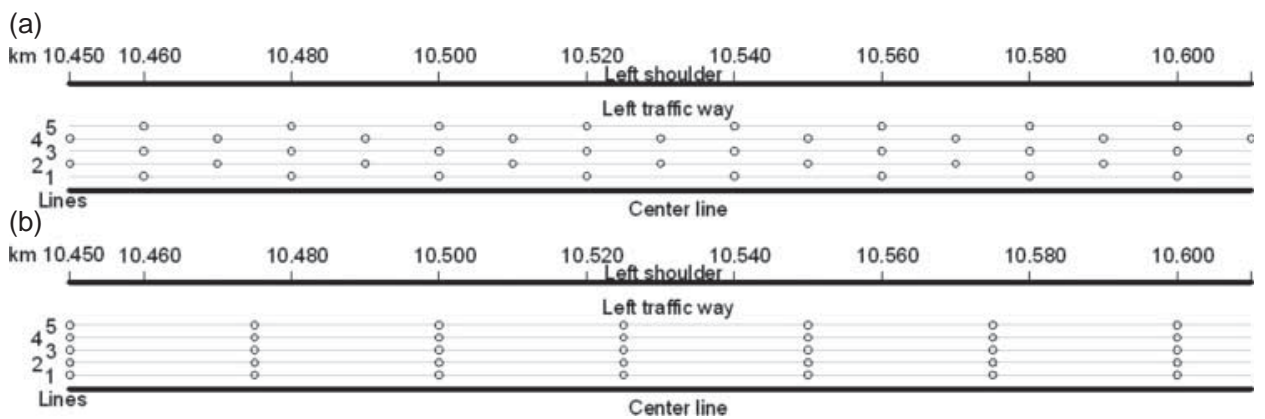

Figure 4. Scheme of the test locations in the base course between 10.450 and $10.610 \mathrm{~km}$ : (a) for all apparatus (FWD; SSG and the nuclear moisture/density gauge) in the upper layer, and for the FWD in the lower layer; (b) for the SSG and the moisture/density gauge in the lower layer. 
In the campaign performed on the upper AIA layer; all the tests were accomplished in the same day and in the same locations (Figure 4(a)), in 41 test locations.

A moisture/density gauge was always used to measure the dry unit weight and the water content of the materials at the SSG test locations.

For the FWD, in each test location, an initial impact for adjustment of the load plate to the surface of the AIA layer was done, followed by three impacts with peak forces of approximately $20 \mathrm{kN}$. As the energy applied in each location can differ, the deflections measured in the last impact were normalized to a force of $20 \mathrm{kN}$. The test conditions and the devices and equipment used were in agreement with the technical specifications and methodology required by the construction consortium, to evaluate the modulus of the granular layers of the pavement (Consulstrada, 2007a, 2007b). A summary of the test conditions with the FWD, including the distances of each geophone to the centre of the load plate, is presented in Table 1.

The tests performed with the SSG were done following an internal procedure, based on the recommendations of the equipment user guide (Humboldt, 2007) and on the standard ASTM D6758 (2008). As the AIA presented a rough surface (Figure 2(a)), it was necessary to use a thin layer of moist sand, around $5 \mathrm{~mm}$ thick, which after being firmly patted allowed a good contact between the base ring (foot) of the SSG and the ground. The SSG was seated and rotated $90^{\circ}$ to both sides, and moderately pressed $(2.5-5.0 \mathrm{~kg})$. In the lower AIA layer, only one measurement in each location was done. In the upper AIA layer, three measurements in each test location were done, and the average value was used. The test conditions used for the SSG are presented in Table 2.

\section{Results}

The results obtained for the dry unit weight $\left(\gamma_{\mathrm{d}}\right)$, stiffness modulus $\left(E_{\mathrm{g}}\right)$ and water content $(W)$ are presented graphically in Figure 5, including all the materials used in the construction (poorly graded sand, silty sand and AIA).

A summary of the deflections measured with the FWD, the stiffness modulus obtained both with the FWD $\left(E_{\mathrm{FWD}}\right)$ and the SSG $\left(E_{\mathrm{g}}\right)$, the dry unit weight $\left(\gamma_{\mathrm{d}}\right)$ and the water content $(W)$ at the time of testing are presented in Table 4. In Figure 6, the results of $E_{\mathrm{FWD}}$ versus $E_{\mathrm{g}}$ are presented for all tested locations.

The representation of the field data distribution in the upper and lower AIA layers of the base course is presented in Figure 7. The contour lines were obtained by triangulation of the data points using linear interpolation. The parameters were obtained according to the test locations presented in Figure 4. 

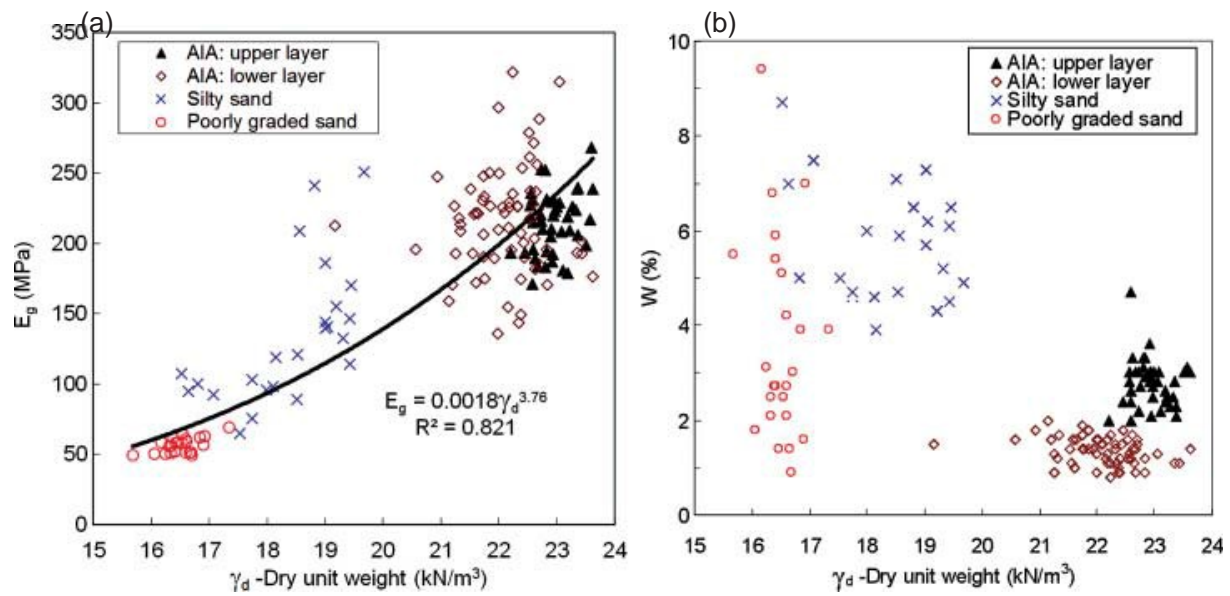

Figure 5. Dry unit weight $\left(\gamma_{\mathrm{d}}\right)$, stiffness modulus obtained with the SSG $\left(E_{\mathrm{g}}\right)$ and water content $(W)$ at the time of testing, for the materials used in the road fill subbase and in the pavement base: (a) $\gamma_{d}$ versus $E_{g}$ and (b) $\gamma_{\mathrm{d}}$ versus $W$.

Table 4. Summary of the field results with the FWD and with the SSG on the AIA layers of the base course.

\begin{tabular}{|c|c|c|c|c|c|c|c|}
\hline Line & & 1 & 2 & 3 & 4 & 5 & Average of 1 to 5 \\
\hline \multicolumn{8}{|c|}{ Upper AIA layer } \\
\hline D1 & Average & 321.50 & 322.00 & 310.63 & 306.22 & 291.38 & 310.34 \\
\hline \multirow[t]{2}{*}{$(\mu \mathrm{m})$} & $\sigma$ & 32.30 & 34.34 & 32.03 & 35.07 & 46.02 & 35.95 \\
\hline & CV (\%) & 10.05 & 10.66 & 10.31 & 11.45 & 15.80 & 11.65 \\
\hline$E_{\mathrm{FWD}}$ & Average & 122.25 & 122.26 & 126.57 & 128.20 & 136.75 & 127.21 \\
\hline \multirow[t]{2}{*}{ (MPa) } & $\sigma$ & 10.83 & 12.36 & 11.39 & 14.13 & 21.54 & 14.05 \\
\hline & CV (\%) & 8.86 & 10.11 & 9.00 & 11.02 & 15.75 & 10.95 \\
\hline$E_{\mathrm{g}}$ & Average & 224.74 & 220.29 & 210.13 & 205.38 & 221.32 & 216.37 \\
\hline \multirow[t]{2}{*}{ (MPa) } & $\sigma$ & 10.48 & 20.22 & 19.21 & 26.92 & 25.71 & 20.51 \\
\hline & CV (\%) & 4.67 & 9.18 & 9.14 & 13.11 & 11.62 & 9.54 \\
\hline$\gamma_{\mathrm{d}}$ & Average & 22.96 & 22.85 & 22.99 & 22.89 & 23.18 & 22.97 \\
\hline \multirow[t]{2}{*}{$\left(\mathrm{kN} / \mathrm{m}^{3}\right)$} & $\sigma$ & 0.31 & 0.24 & 0.39 & 0.20 & 0.40 & 0.31 \\
\hline & CV (\%) & 1.33 & 1.04 & 1.71 & 0.87 & 1.72 & 1.33 \\
\hline$W$ & Average & 2.69 & 2.65 & 2.84 & 3.00 & 2.89 & 2.81 \\
\hline \multirow[t]{2}{*}{ (\%) } & $\sigma$ & 0.40 & 0.43 & 0.41 & 0.79 & 0.30 & 0.47 \\
\hline & CV (\%) & 14.81 & 16.39 & 14.34 & 26.35 & 10.38 & 16.45 \\
\hline \multicolumn{8}{|c|}{ Lower AIA layer } \\
\hline \multicolumn{2}{|c|}{ Line } & 1 & 2 & 3 & 4 & 5 & Average of $1-5$ \\
\hline D1 & Average & 297.29 & 261.29 & 252.29 & 269.54 & 264.60 & 269.01 \\
\hline \multirow[t]{2}{*}{$(\mu \mathrm{m})$} & $\sigma$ & 37.22 & 51.65 & 63.95 & 65.59 & 81.38 & 59.96 \\
\hline & CV (\%) & 12.52 & 19.77 & 25.35 & 24.33 & 30.76 & 22.54 \\
\hline$E_{\mathrm{FWD}}$ & Average & 133.00 & 154.05 & 163.56 & 152.08 & 158.50 & 152.24 \\
\hline \multirow[t]{2}{*}{ (MPa) } & $\sigma$ & 17.03 & 28.78 & 43.14 & 35.88 & 45.62 & 34.09 \\
\hline & CV (\%) & 12.81 & 18.68 & 26.38 & 23.60 & 28.78 & 22.05 \\
\hline & Average & 224.43 & 222.14 & 217.84 & 226.26 & 195.00 & 217.13 \\
\hline \multirow{2}{*}{$\begin{array}{l}\mathrm{Lg} \\
\text { (MPa) }\end{array}$} & $\sigma$ & 54.79 & 35.45 & 19.91 & 50.88 & 38.87 & 39.98 \\
\hline & CV (\%) & 24.42 & 15.96 & 9.14 & 22.49 & 19.33 & 18.39 \\
\hline & Average & 22.42 & 22.36 & 21.83 & 22.41 & 21.95 & 22.19 \\
\hline \multirow{2}{*}{$\left(\mathrm{kN} / \mathrm{m}^{3}\right)$} & $\sigma$ & 0.63 & 0.33 & 0.68 & 0.59 & 0.57 & 0.56 \\
\hline & CV (\%) & 2.83 & 1.49 & 3.11 & 2.65 & 2.62 & 2.54 \\
\hline$W$ & Average & 1.32 & 1.37 & 1.63 & 1.41 & 1.46 & 1.44 \\
\hline \multirow[t]{2}{*}{ (\%) } & $\sigma$ & 0.25 & 0.18 & 0.18 & 0.28 & 0.39 & 0.26 \\
\hline & CV (\%) & 18.86 & 13.12 & 11.05 & 19.76 & 26.83 & 17.92 \\
\hline
\end{tabular}

Note: $\sigma$, standard deviation; $C V$, coefficient of variation. 


\section{Discussion}

For a suitable evaluation of the results, the reader should be aware that the parameters measured or calculated correspond to post-construction conditions, as the 'in situ' data acquisition was performed one week after the layers construction.

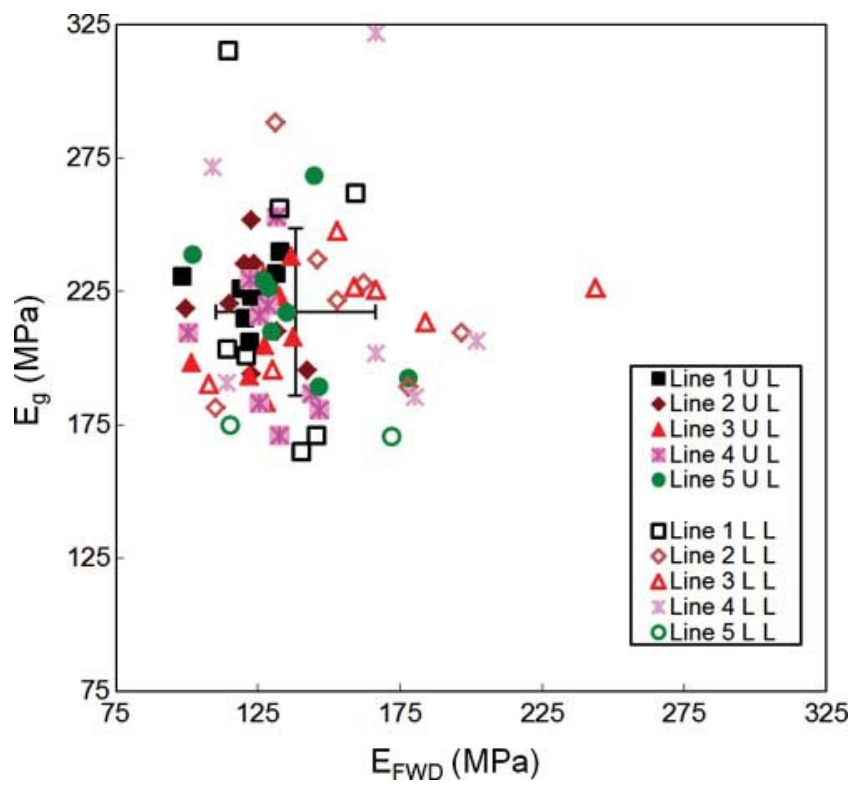

Figure 6. Results of $E_{\mathrm{FWD}}$ versus $E_{\mathrm{g}}$. The average and the standard deviation of both $E_{\mathrm{FWD}}$ and $E_{\mathrm{g}}$ are plotted (UL - upper layer; LL - lower layer).

\subsection{Granular material properties}

A positive trend between the dry unit weight $\left(\gamma_{\mathrm{d}}\right)$ and the SSG stiffness modulus $\left(E_{\mathrm{g}}\right)$ for the three materials tested (AIA, silty sand and poorly graded sand) is presented in Figure 5(a). The equation that best fits the results is

$$
E_{\mathrm{g}}(\mathrm{MPa})=0.0018, \mathrm{~d}^{3.76} R^{2}=0.821
$$

considering $\gamma_{\mathrm{d}}$ to be in $\mathrm{kN} / \mathrm{m}^{3}$.

The poorly graded sand has the lower values, both for $E_{\mathrm{g}}$ and for $\gamma_{\mathrm{d}}$, as they are aeolian sands, difficult to compact. The in-place large range of water content measured for this soil (Figure 5(b)) can be attributed to the spraying of the construction area with water, to avoid dust during the dry period when the tests were executed. From Figure 5, it also can be concluded that the poorly graded sand presents a larger dispersion for the dry unit weight than for the stiffness modulus.

The silty sand has the wider range of values, both for the dry unit weight and for the stiffness modulus, due to their wide grain size distribution.

Concerning the five parameters of the AIA presented in Table 4 and in Figure $7\left(\mathrm{D} 1, E_{\mathrm{FWD}}, E_{\mathrm{g}}, \gamma_{\mathrm{d}}\right.$ and $\left.W\right)$, the unique significant correlation obtained is between D1 and $E_{\mathrm{FWD}}$, because D1 is used to calculate $E_{\mathrm{FWD}}$. Despite this, it is possible to observe in Figure 7 that the distribution of the contours of each individual parameter presents a rough similarity in each layer. For the FWD, 
small deflections D1 correspond to high $E_{\mathrm{FWD}}$. High values of unit weight are expected to correspond to high stiffness modulus. The water content at the time of testing cannot be related with any other parameter because it is mainly dependent on the weather and on the spraying of the construction area.

Analysing individually each parameter, some considerations can be presented. For the AIA used in the base course, the stiffness modulus is around $217 \mathrm{MPa}$ for $E_{\mathrm{g}}$ or around $140 \mathrm{MPa}$ for $E_{\mathrm{FWD}}$, while the dry unit weight presents a distribution around $22.5 \mathrm{kN} / \mathrm{m}^{3}$, corresponding to the maximum obtained in the modified effort test. Considering separately the lower and the upper AIA layers, some differences can be noticed.

Upper AIA layer
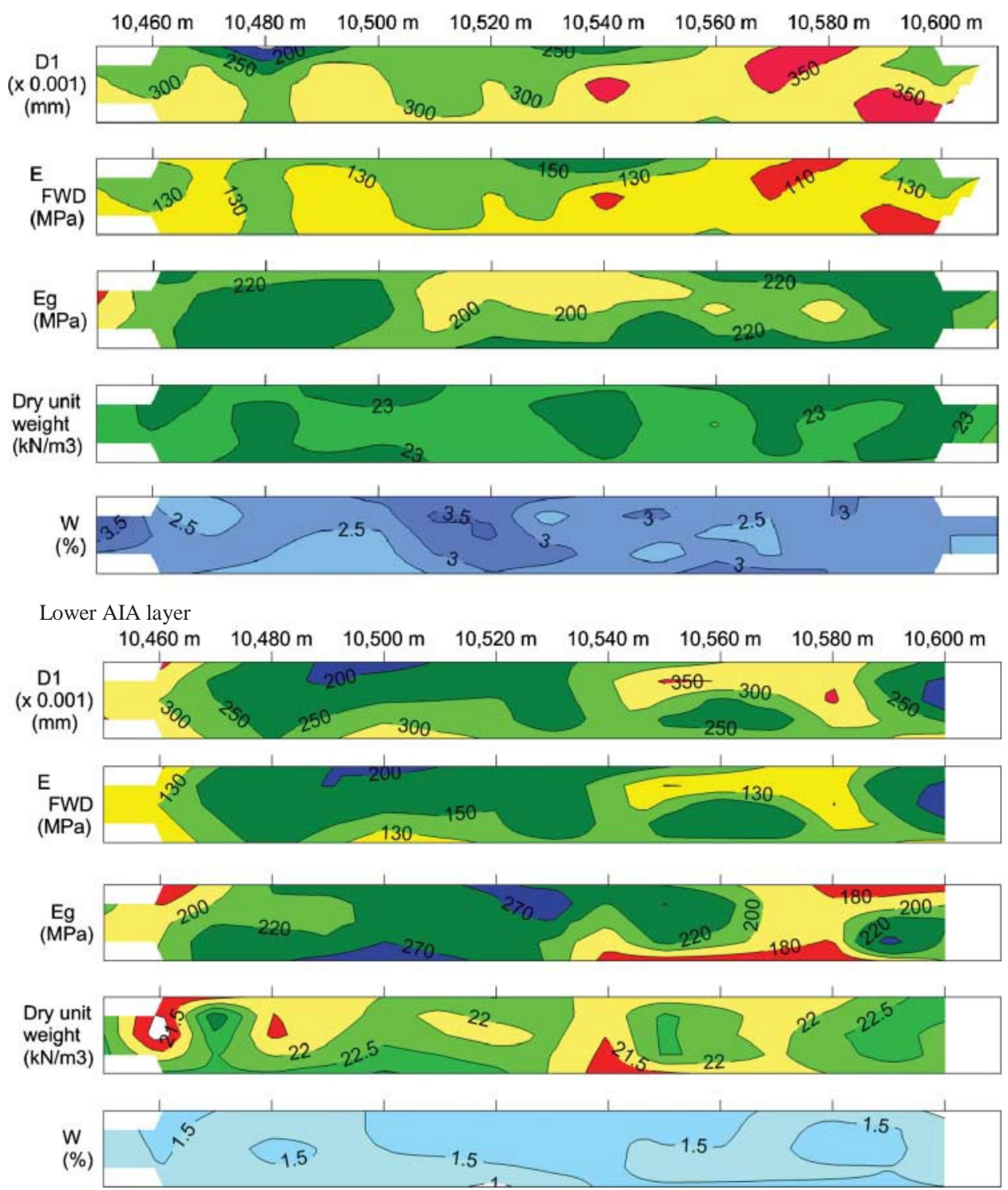

Figure 7. Representation of the field data distribution in the upper and lower AIA layers of the base course. The scheme of the test locations is presented in Figure 4. 
As shown in Table 4, the stiffness modulus parameters for $E_{\mathrm{FWD}}$ and for $E_{\mathrm{g}}$ present a different behaviour in the two layers. The average value decreases from the lower to the upper layer (152-127 MPa for $E_{\mathrm{FWD}}$ and from 217 to $216 \mathrm{MPa}$ for $E_{\mathrm{g}}$ ), showing an increase in the average deformability of the upper layer. Complementarily, the standard deviation and the coefficient of variation, both decrease in the upper layer indicating that in spite of the lower stiffness modulus, the upper layer is more homogeneous. The lower AIA layer has an average $\gamma_{\mathrm{d}}$ of $22.2 \mathrm{kN} / \mathrm{m}^{3}$, while the upper layer exhibits a higher average of $23.0 \mathrm{kN} / \mathrm{m}^{3}$. The increase in the dry unit weight and the reduction of the coefficient of variation in the upper AIA layer do not have correspondence to an increase in the stiffness modulus, as shown in Figures 5, 7 and in Table 4.

Due to drying, the average water content of both AIA layers (1.4\% and 2.8\%) is significantly lower than the target values considered during compaction (5.2\%), and thus the water content measured cannot be used for quality control purposes. The upper AIA layer has the higher water content $(2,8 \%)$ and the higher dry unit weight (Figures 5, 7 and Table 4), but it has no relevant influence on the stiffness modulus that is lower.

As the coefficients of variation evaluate the relative closeness of the predictions to the actual values, the data presented in Table 4 show that the upper layer has coefficients of variation under $17 \%$, being more homogeneous than the lower layer presenting coefficients of variation under $23 \%$.

\subsection{Moduli comparison of side-by-side tests}

A comparison between the moduli of the FWD and of the SSG was done, assuming the tests were done side-by-side, on a homogeneous half space. For the FWD, the stiffness modulus $\left(E_{\mathrm{FWD}}\right)$ was calculated, for each point, using the deflections (D1) in the centre of the plate. For the SSG, the stiffness modulus $\left(E_{\mathrm{g}}\right)$ was obtained by in situ tests. For both procedures, Poisson's ratio of 0.35 was used.

Both moduli ( $E_{\mathrm{FWD}}$ and $E_{\mathrm{g}}$ ) were plotted for each test location (Figure 6), but no significant correlation was obtained. The results presented in Figure 6 show an average of $138 \mathrm{MPa}$ and a standard deviation of $28 \mathrm{MPa}$ for $E_{\mathrm{FWD}}$, while an average of $217 \mathrm{MPa}$ and a standard deviation of $31 \mathrm{MPa}$ was obtained for $E_{\mathrm{g}}$. The proportion between the average values of these two techniques is $E_{\mathrm{g}}=1.57 E_{\text {FWD }}$. It is stressed that this proportion should not be considered a correlation, because in fact no significant correlation between individual values was obtained. A similar conclusion was obtained by George (2001), who stated, that his study on soil-cement, failed to confirm a one-to-one relation between the moduli of these two devices.

The lack of correlation between the results of these two techniques can be attributed to the large number of variables influencing the moduli: the bulb of ground tested by each technique due to the different dimension of the plates; the type of solicitation induced to the ground (strike of a falling mass for the 
FWD and 25 frequencies of vibration during one minute for the SSG); the water content at the time of testing; the differences in the distribution and packing of individual granular particles in the layer due to spreading, compaction and circulation of vehicles during the construction operations.

\subsection{Moduli comparison using backanalysis}

For the FWD, all deflections were normalised to an impact force of $20 \mathrm{kN}$, and a statistical analysis of the deflections was done, seeking for values that could be considered outliers. For the lower layer, no outliers were considered. In the upper layer, 5 data points were considered as outliers and were excluded, one in each row, and the average for $D_{1}$ became $290 \mu \mathrm{m}$, the standard deviation 36 $\mu \mathrm{m}$, these values being slightly different from the ones presented in Table 4 .

The stiffness modulus was computed by back analysis using the computer program ELSYM5, developed by the University of California, considering the 85th percentile of the deflections $\left(D^{85}\right)$, obtained by the equation $\mathrm{D}^{85}=$ Average $+1.036 \sigma$. An approach between the calculated deflections bowl and the measured ones was sought (Consulstrada, 2007a, 2007b).

The back analysis used for the FWD calculates separately the stiffness modulus for the founda- tion and for the pavement layers. For the SSG, the stiffness modulus obtained corresponds to the thickness between the surface and a depth up to $31 \mathrm{~cm}$, as described in the equipment user guide (Humboldt, 2007). To overcome this difference, conditions that could be considered equivalent were defined, allowing the results of the two methods to be compared.

For the FWD, the equivalent module for a total thickness of $30 \mathrm{~cm}$ was calculated, using the methodology based on the analysis of elastic structures done by Odemark (Jung \& Phang, 1974), stating that the deflection of an elastic layer of thickness $h$ and module $E$, under the action of a circular load, is proportional to the product $E h^{3}$. This procedure allowed calculating an equivalent foundation surface modulus ( $\left.E_{\text {eq }}\right)$ for the lower and upper AIA layers (Table 5). For the SSG, to make the analysis in a similar way to the FWD, the stiffness modulus of the SSG was calculated for the percentile $85\left(E^{85}\right)$ using the equation $E^{85}=$ Average- $1.036 \sigma$.

In Table 5, the parameters that can be considered comparable are $E_{\text {eq }}$ and $E^{85}$, because they were computed in a similar manner. $E_{\text {eq }}^{g}$ was computed using the 85th percentile, of the deflections, and for an equivalent thickness of $30 \mathrm{~cm} . E^{85}$ was computed for the 85th percentile of the stiffness modulus and a thickness up to $31 \mathrm{~cm}$. Comparing $E_{\text {eq }}$ (FWD) with $E^{85}$ (SSG) an average difference of $+15 \%$ was obtained in the lower AIA layer, while an average of $-20 \%$ was obtained in the upper AIA layer (Table 5). 
Table 5. Comparison of the stiffness modulus calculated for the FWD and the SSG on the AIA layers of the base course.

\begin{tabular}{|c|c|c|c|c|c|c|c|c|c|c|}
\hline \multirow[t]{2}{*}{ Upper AIA layer } & \multicolumn{6}{|c|}{ FWD } & \multicolumn{3}{|c|}{ SSG } & \multirow{3}{*}{$\begin{array}{l}85 \\
(\%)\end{array}$} \\
\hline & Upper & layer & Lower & Layer & & & & & & \\
\hline Line & $h_{\mathrm{U}}(\mathrm{cm})$ & $E_{\mathrm{U}}(\mathrm{MPa})$ & $h_{\mathrm{L}}(\mathrm{cm})$ & $E_{\mathrm{L}}(\mathrm{MPa})$ & $E_{\mathrm{S}}(\mathrm{MPa})$ & $E_{\mathrm{eq}}(\mathrm{MPa})$ & $h_{\mathrm{g}}(\mathrm{cm})$ & $E_{\mathrm{g}}(\mathrm{MPa})$ & $E_{\mathrm{g}}^{\mathrm{Cb}}(\mathrm{MPa})$ & \\
\hline \multirow[t]{2}{*}{1} & 15 & 320 & 15 & 180 & 102 & 243 & 31 & 225 & 214 & -12.0 \\
\hline & 15 & 320 & 15 & 180 & 100 & 243 & 31 & 220 & 199 & -18.0 \\
\hline 3 & 15 & 320 & 15 & 180 & 100 & 243 & 31 & 210 & 190 & -21.7 \\
\hline 4 & 15 & 320 & 15 & 180 & 103 & 243 & 31 & 205 & 177 & -27.0 \\
\hline 5 & 15 & 320 & 15 & 185 & 111 & 246 & 31 & 221 & 195 & -20.9 \\
\hline Average & & 320 & & 181 & 103 & 244 & & 216 & 195 & -19.9 \\
\hline \multirow[t]{2}{*}{ Lower AIA layer } & \multicolumn{4}{|c|}{ FWD } & \multicolumn{3}{|c|}{ SSG } & & & \\
\hline & Lower & layer & Subbase & $F$ & & & & $\mathrm{~A}^{85}$ & & \\
\hline Line & $h_{\mathrm{L}}(\mathrm{cm})$ & $E_{\mathrm{L}}(\mathrm{MPa})$ & $E_{\mathrm{S}}(\mathrm{MPa})$ & $E_{\text {eq }}(\mathrm{MPa})$ & $h_{\mathrm{g}}(\mathrm{cm})$ & $E_{\mathrm{g}}(\mathrm{MPa})$ & $E_{\mathrm{g}}^{\mathrm{Cb}}(\mathrm{MPa})$ & $(\%)$ & & \\
\hline 1 & 15 & 185 & 137 & 160 & 31 & 224 & 168 & 4.8 & & \\
\hline 2 & 15 & 180 & 123 & 150 & 31 & 222 & 185 & 23.6 & & \\
\hline 3 & 15 & 180 & 126 & 151 & 31 & 218 & 197 & 30.6 & & \\
\hline 4 & 15 & 180 & 137 & 158 & 31 & 226 & 174 & 9.8 & & \\
\hline 5 & 15 & 185 & 127 & 154 & 31 & 212 & 165 & 7.4 & & \\
\hline Average & & 182 & 130 & 155 & & 221 & 178 & 15.2 & & \\
\hline
\end{tabular}

Note: FWD: $h_{\mathrm{U}}$ and $h_{\mathrm{L}}$ - thickness of the upper (U) and of lower (L) granular layers; $E_{\mathrm{U}}, E_{\mathrm{L}}$ and $E_{\mathrm{S}}$-stiffness modulus of the upper layer, lower layer and of the subbase. $E_{\mathrm{e}}$ - equivalent surface foundation modulus of $E_{\mathrm{U}}$ and $E_{\mathrm{L}}$ or $E_{\mathrm{L}}$ and $E_{\mathrm{S}}$. SSG: $h_{\mathrm{g}}$ - measurements depth; $E_{\mathrm{g}}$ and $E^{85} \mathrm{~g}^{-}$stiffness modulus for the average $\left(E_{\mathrm{g}}\right)$ and for the $85^{\text {th }}$ percentile. ${ }^{85}-\operatorname{Differential}\left(E_{\mathrm{g}}^{85}-E_{\mathrm{eq}}\right) / E_{\mathrm{eq}} \times 100$. 
The discrepancies in the results of the two techniques can be understood by the different approaches used to obtain the modulus and by several factors that can influence the stiffness modulus such as the distribution and packing of the granular layer materials associated with the construction procedures, the ageing of the layers and to the effect of the underlying layers. In the lower layer, the use of different test locations for the FWD and the SSG, and the use of only one reading in each test place with the SSG, did not appear to have a relevant effect on the average of the results.

\section{Conclusions}

Based on the data obtained over the range of granular materials used in the road construction, it was observed that the dry unit weight $\left(\gamma_{\mathrm{d}}\right)$ is related with the stiffness modulus $\left(E_{\mathrm{g}}\right)$. For each single material, a cluster can be identified.

As both the AIA used in the layers and the equipment and construction techniques were the same, it was verified that even testing a single material, in consecutive layers, slightly different values could be obtained. The differences can be attributed to: the distribution and packing of the granular particles in the layers associated with the construction procedures and to the ageing of the layers, and to the effect of the underlying layers.

Considering each single test point, it was verified that the stiffness modulus obtained with both equipment ( $E_{\mathrm{FWD}}$ and $E_{\mathrm{g}}$ ) are not correlated. Despite that the average value of $E_{\mathrm{g}}$ is 1.57 times higher than $E_{\mathrm{FWD}}$, and $E_{\mathrm{g}}$ presents a lower coefficient of variation than $E_{\mathrm{FWD}}$.

With the two test procedures used (van-integrated FWD and SSG), a postconstruction in-place stiffness modulus evaluation of compacted AIA materials, used in pavement base course, was performed.

The moduli $g$ comparison using back analysis showed a relevant similarity of values between the moduli obtained with the two test procedures. Taking as reference the FWD, the average moduli obtained with the two equipment, computed for the 85th percentile, showed a difference lower than $\pm 20 \%$. The use of the 85th percentile ( $\mathrm{D}^{85}=$ Average $+1.036 \sigma$ for the deflections of the FWD and $E^{85}=$ Average $-1.036 \sigma$ for the stiffness modulus of the SSG) allowed a good coherence of both results.

The development of reliable and easy procedures for the in situ stiffness modulus evaluation of granular pavement layers, using a lightweight equipment of moderate cost, such as the SSG, has great advantages, allowing the verification of the stiffness modulus of the layers, with significant savings in costs and time.

The procedure used in this paper will be applied to other materials, in further researches, in order to verify the influence of the materials type on the results. 


\section{References}

Abu-Farsakh, M.Y., Alshibli, K., Nazzal, M., \& Seyman, E. (2004). Assessment of in-situ test technology for construction control of base courses and embankments (126pp.). Technical Report no FHWA/LA.04/385. Baton Rouge, LA, USA: Louisiana Transportation Research Center.

Alshibli, K.A., Abu-Farsakh, M., \& Seyman, E. (2005). Laboratory evaluation of the geogauge and light falling weight deflectometer as construction control tools. Journal of Materials in Civil Engineering ASCE, 17(5), 560569.

ASTM D6758. (2008). Standard test method for measuring stiffness and apparent modulus of soil and soil aggregate in-place by an electromechanical method. West Conshohocken, PA: American Society for Testing and Materials, ASTM International.

Batista, L.M. (2007). Determinação de parâmetros de deformabilidade de camadas de um pavimento a partir de ensaios de campo (Master of Science thesis, G.DM-159/07, Dep. Engenharia Civil e Ambiental, University of Brasília, Brasília, DF), 182pp. (in Portuguese).

Consulstrada. (2007a, October, 23). A17 - sublanço Tocha/ Mira. Avaliação da capacidade de carga do pavimento. Ensaios de carga com deflectómetro de impacto na camada de subbase em (in Portuguese).

Consulstrada. (2007b, November, 31) A17 - sublanço Tocha/ Mira. Avaliação da capacidade de carga do pavimento. Ensaios de carga com deflectómetro de impacto na camada de base em (in Portuguese).

Fleming, P.R., Rogers, C.D.F., \& Frost M.W. (1998). Performance parameters and target values for construction of UK road foundations. 5th International conference on the bearing capacity of roads and airfields (Vol. 3, pp. 1491-1501), Trondheim, Norway.

Garcia, G., \& Thompson, M.R. (2003). Subgrade strength/stiffness evaluation. Transportation Research Laboratory, Department of Civil \& Environmental Engineering, University of Illinois, USA.

George, K.P. (2001). Soil stabilization field trial. Interim Report I to Mississippi Department of Transporta- tion, University of Mississippi.

George, K.P. (2006). Portable FWD (Prima 100) for in-situ subgrade evaluation. Final Report, Department of Civil Engineering, University of Mississippi.

Humboldt (2007). GeoGauge ${ }^{T M}$ user guide. Model H-4140. Soil stiffness/ modulus gauge (Version 4.0).

Norridge, IL: Humboldt Mfg. Co.

IAN73/ 06 revision 1. (2009). Design guidance for road pavement foundations (Draft HD25). London: Highways Agency (HA).

Jung, F., \& Phang, W.A. (1974). Elastic layer analysis related to performance in flexible pavement design.

Issue no. 521. Washington: Transportation Research Board.

LCPC. (2004). Dynaplaque-2. France: Laboratoire Central des Ponts et 
Chaussées. Retrieved August 3, 2012, from http://www.lcpc.fr/

Mohammad, L.N., Nazzal, M.D., Abu-Farsakh, M.Y., \& Alshibli, K. (May 2009). Estimation of subgrade soils resilient modulus from in-situ devices test results. Journal of Testing and Evaluation, 37(3), 245-253.

Nazzal, M.D. (2003). Field evaluation of in-situ test technology for Qc/Qa during construction of pavement layers and embankments (Master of Science thesis in Civil Engineering, Louisiana State University).

Nazzal, M.D., Abu-Farsakh, M., Alshibli, K., \& Mohammad, L.N. (2007). Deflectometer device for in situ measurement of elastic modulus of pavement layers. Transportation research record: Journal of the Transportation Research Board, 2016, 13-22.

NF P 94-117-2. (2004). Sols: Reconnaissance et essais - Portance des plateformes - Partie 2: module sous chargement dynamique. Association Française de Normalisation (AFNOR) (in French).

Quinta-Ferreira, M., Andrade, P.S., Branco, F.C., \& Fung, E. (2008b). Alguns resultados do Geogauge e do deflectómetro de impacto (FWD) na caracterização de pavimentos. IV Cong. Luso-Brasileiro de Geotecnia (pp. 161-168), Coimbra (in Portuguese).

Quinta-Ferreira, M., Andrade, P.S., \& Oliveira, M.A. (2008a). Caracterização da deformabilidade com o Geogauge. IV Cong. Luso-Brasileiro de Geotecnia (pp. 129-136), Coimbra (in Portuguese).

Sawangsuriya, A. (May 2006). Application of soil stiffness gauge in assessing small-strain stiffness of sand with different fabrics and densities. Geotechnical Testing Journal, 29(3), 207-216.

Seyman, E. (2003). Laboratory evaluation of in-situ tests as potential quality control/quality assurance tools (Master of Science Thesis in Civil Engineering, Louisiana State University).

TP BF-StB, Part B 8.3. (2003). Technische Prüfvorschrift für Boden und Fels im Straßenbau, Dynamischer Plattendruckversuch mit dem Leichten Fallgewichtsgerät. FGSV - Forschungsgesellschaft fuer Strassen- und Verkehrswesen (German Road and Transportation Research Association) (in German). 